\title{
ROMA IMPERIAL E CHINA: COMUNICAÇÃO E TRANSMISSÃO DE INFORMAÇÕES1
}

Anne Kolb²

Michael A. Speidel ${ }^{3}$

Como principais potências mundiais, o Imperium Romanum e o antigo Império Chinês das dinastias Qin e Han existiam contemporaneamente desde meados do século II AEC até a primeira metade do século III EC. Entre eles, calcula-se que controlavam metade da população mundial (Scheidel, 2015: 5). No entanto, eles não dispunham de uma fronteira comum. Eles foram separados pela enorme distância entre as extremidades opostas do continente eurasiano e uma topografia proibitiva que incluía algumas das montanhas mais altas e os desertos mais mortíferos do planeta. No entanto, particularmente a partir do primeiro século EC, fontes de ambos os impérios antigos registram um crescente intercâmbio comercial e diplomático, bem como um interesse significativo em relatos escritos sobre o outro. Dependendo do valor atribuído a essas fontes, estudiosos modernos propuseram visões contraditórias de impérios independentes ou interativos. Assim, argumentou-se recentemente que "os dois impérios mundiais permaneceram ocultos um ao outro em um reino crepuscular de fábula e mito" e que eles inconscientemente participaram "de um grande sistema mundial de comércio que havia se desenvolvido, enquanto poucos, se tanto, dos participantes sabiam muito sobre os outros " (Fibiger Bang, 2009: 120; Loewe, 2010: 83). Isso, por sua vez, levou outros a concluírem que ambos os impérios tinham interação mínima e se desenvolviam independentemente um do outro, criando assim uma oportunidade ideal para estudos de história comparativa (Scheidel, 2015: 5). Outros, entretanto, pressupõem contato rotineiro. Assim, em um livro recente sobre geografia na Antiguidade Clássica, um erudito afirmou que "os romanos chegaram até a China, estabelecendo contatos com [a população] local". Os romanos, segundo nos dizem, "negociavam com os chineses e tinham contatos recíprocos com a corte já no tempo de Augusto" (Dueck, 2012: 62). Os

\footnotetext{
${ }^{1}$ Este texto foi publicado originalmente como capítulo do livro China's Development from a Global Perspective (Capítulo II), organizado por María Dolores Elizalde e Wang Jianlang (Cambridge: Cambridge Scholars, 2017); foi traduzido com a anuência do autor e da editora. Tradução de Jéssica Regina Brustolin - jessica.brustolim@usp.br

2 Professora de História Antiga do Departamento de História da Universidade de Zurique.

3 Professor de História Antiga do Instituto de Arqueologia da Universidde de Warsaw.
}

Heródoto, Unifesp, Guarulhos, v.4, n.1 - 2019.1. p. 395-422

DOI: 10.34024/herodoto.2019.v4.10128 
primeiros adeptos dessa escola de pensamento chegaram a sugerir que, em 122 EC, o imperador romano Adriano ordenou a construção do grande muro de pedra no norte da província da Britânia porque os relatos de viajantes sobre a Grande Muralha da China o haviam inspirado (Stevens, 1955: 397-399, Breeze, Dobson, 1976: 32. Cf. Campbell, 1989: 371-376). Uma reavaliação do fluxo de informação entre os dois grandes impérios, da natureza e do estado em que os dados foram preservados, e dos canais e agentes que os transmitiram, parece, portanto, apropriada.

\section{Dados Ocidentais}

No quinto século AEC, a seda chinesa alcançara o Oeste (Miller, 1997: 77). A China, no entanto, permaneceu desconhecido para seus contemporâneos ocidentais. Assim, embora Heródoto pareça ter sabido de uma rota comercial, usada por citas e gregos, que conectava o Mar Negro à Ásia Central (Hdt, 23-25. Cf. 101), seus informantes não tinham nada além de histórias fantasiosas baseadas em rumores e boatos sobre as criaturas, povos e países além da barreira montanhosa adjacente 4 . De acordo com os relatórios que ele coletou (mas se recusou a acreditar), essas montanhas eram habitadas por homens com pés de cabra e, além deles, havia um povo que dormia durante seis meses do ano. Ele também ouviu falar de homens de um olho só e grifos de guarda feitos de ouro no lado mais próximo das montanhas. Mais de um século depois, nos anos 334-326 AEC, Alexandre, o Grande, conquistou os países entre o Mediterrâneo oriental e o Punjabi. No entanto, mesmo agora, a literatura ocidental não tinha nada confiável a dizer sobre os chineses.

Mas as conquistas de Alexandre e, mais de 100 anos depois, a unificação da China em 221 AEC sob o seu primeiro imperador Qin Shihuang, estabeleceram as bases que, eventualmente, permitiriam o sucesso inigualável do antigo comércio de longa distância que se desenvolveu ao longo da rede de rotas que nós, atualmente, chamamos de "Rota da Seda" (Hill, 2015; Liu, 2010; Graf, 2017; Olbrycht, 2013; Nickel, 2013). Ainda assim, segundo a tradição, demorou mais um século até que a rota comercial se tornasse totalmente operacional no final do segundo século AEC, pois isso foi o resultado do estabelecimento dos reinos selêucidas e depois dos partas na Pérsia, do reino de Maurya, na Índia, e da grande expansão chinesa sob o imperador Han $\mathrm{Wu}$ (156-87 AEC). O vasto tamanho desses

\footnotetext{
${ }^{4}$ Ver Hdt. 4, 13.4, 25-27, com a interpretação de Walter, 2009, pp. 87-93 e Walter, 2013, pp. 67-73.
}

Heródoto, Unifesp, Guarulhos, v.4, n.1 - 2019.1. p. 395-422

DOI: 10.34024/herodoto.2019.v4.10128 
reinos, seu número comparativamente pequeno, a vontade de seus governantes e sua autoridade menos adequada criaram um ambiente favorável ao comércio de longa distância, inclusive no que diz respeito aos custos de proteção e tributação. Desde o final do segundo século AEC, o mais tardar, um fluxo de comércio, emissários e informações surgiram entre esses reinos. Em meados do século IV EC, o historiador romano Amiano Marcelino, sem uma noção de surpresa, menciona "um caminho muito longo" (iter longissimum) através da Ásia Central que "freqüentemente" ou "periodicamente" (em todo caso, recorrente: subinde) levou mercadores a passar por um lugar chamado "Torre de Pedra" para a terra dos "Seres" (Povo da Seda) cujo país rico e vasto era rodeado de "grandes muros" 5 .

Amiano também sabia de uma rota comercial marítima que ligava o Mediterrâneo oriental com a Índia e a terra dos Seres, e que trazia bens para mercados na parte oriental do Império Romano (Osrhoenian Batnae, em particular) (Amm. 14, 3, 3). O sistema de comércio de longa distância entre o Oriente e o Ocidente só alcançou seu estado final e mais completo na Antiguidade após a conquista do Egito por Roma em 30 AEC. A tomada do Egito por Roma não só uniu politicamente toda a bacia do Mediterrâneo, mas também estabeleceu a rota marítima através do Mar Vermelho e no Oceano Índico como uma alternativa econômica e, assim, incluindo-a no sistema de comércio das "Rotas da Seda" (Speidel, 2015). Como resultado, as rotas comerciais ligavam o Oceano Atlântico ao Pacífico. Embora mercadores do Império Romano tenham comprado, inicialmente, mercadorias chinesas na índia (PME 64-5), alguns parecem ter navegado até a Birmânia moderna, o Camboja e o Vietnã (Jos., AJ 8,6, 4ff. Ptol. 1,14. Liang-Shu, 54. Wei-Shu, 102; Ferguson, 1978: 586, Hill, 2015: 291ff). Desde o final do primeiro século AEC, bens exóticos da Índia e da China estavam sendo vendido em Roma e em mercados em todo o mundo romano em quantidades razoavelmente grandes (Graf, 2017). Como era de se esperar, parece que a China estava firmemente integrada ao conceito ocidental do mundo habitado, o oikumene ${ }^{6}$.

Certamente não é coincidência que, na época em que os autores ocidentais começaram a tomar conhecimento da China e dos chineses, ou seja, a

\footnotetext{
5 Amm. 23, 6, 60: Praeter quorum radices et vicum, quem Lithinon Pyrgon appellant, iter longissimum patet, mercatoribus pervium, ad Seras subinde commeantibus. "Grandes Muros": Amm. 23, 6, 64. Campbell, 1989: 374, considera que esta é uma "descrição poética das montanhas".

${ }^{6}$ Cf. a pesquisa de fontes ocidentais de Ferguson, 1978: 581-603, a qual também pode se adicionar a Tabula Peutingeriana. Sobre ela, cf. Speidel, inédito, e McLaughlin, 2010: 131132.
}

Heródoto, Unifesp, Guarulhos, v.4, n.1 - 2019.1. p. 395-422

DOI: 10.34024/herodoto.2019.v4.10128 
primeira metade do primeiro século AEC, a seda se tornara um bem de luxo bem conhecido e altamente desejável em Roma e no Oriente helenístico (Ferguson, 1978: 592; Strabo, 11,11,1. Cf. Poinsotte, 1979: 432f). O significado dos chineses para os gregos e romanos é imediatamente traído pelo nome que receberam: "Seres", o "Povo da Seda" (Ptol, 11,11. 15,1). Aparentemente, o verdadeiro nome do "Povo da Seda" era ainda desconhecido para os autores ocidentais. Ainda assim, eles, unanimemente, os localizaram nas partes mais orientais do mundo habitado, ocasionalmente associando-os a outros povos (mais conhecidos) do Oriente distante (Cf. e.g. Strabo 11,11,1. Hor., Carm. 1, 12, 56. 3, 29, 227. 4, 15, 23. Pomp. Mela 1,11. PME 64-65. Ptol. 1, 11. Amm. 23, 6, 60. Hld. 9,1618. TP 11 B 5). No entanto, o conhecimento geográfico do Extremo Oriente nas obras sobreviventes de geógrafos ocidentais era, principalmente, nebuloso. Assim, por exemplo, Pomponio Mela escreveu: “Os Seres habitam aproximadamente a parte central do Oriente, com os índios e citas nas extremidades, ambos ocupando amplas faixas e se espalhando, não apenas neste lugar, para o oceano" (Mela 1,11). Portanto, permanece impossível estabelecer, sem sombra de dúvida, se o termo "Seres" se referia aos chineses ou aos intermediários (por exemplo, da bacia de Tarim), para localizar sua capital Sera, para definir sua relação exata com o termo "Thina (e)" /"Sinai" de Ptolomeu e de Periplus (PME 64-65. Ptol. 7, 3, 1. 7, 3,6 .), ou mesmo para estabelecer se todas as referências na literatura ocidental antiga aos Seres são sobre uma única e mesma população7 .

Os Seres eram retratados como um povo de modos inofensivos, mais conhecidos pelo comércio (commercium) que administravam, embora fossem acusados do hábito bárbaro de evitar o intercurso com o resto da humanidade, aguardando a aproximação daqueles que desejavam traficar com eles (Mela 3,60. Plin., NH 6, 20, 54). Com alguns autores ocidentais, eles também tinham a reputação de serem excelentes arqueiros e cocheiros, bem como de viver vidas longas e serem particularmente justos (Hor., Carm. 1, 29, 7ff. Prop. 4, 8, 23). No início do século III EC, Bardaisan, um filósofo e membro da corte real de Edessa, no norte da Mesopotâmia (e, portanto, de um ramo importante da "Rota da Seda"), elogiou os chineses por terem leis e tribunais legais que estruturavam e regulavam suas vidas diárias (ao invés de superstição astrológica) ("Livro das Leis dos Países" 116ff. Cf. Euseb., P.E. 6, 10, 12f, e Caesarius 2, 109). Também no século III, Celso e Orígenes acreditavam que os Seres eram ateus (uma referência ao ceticismo confucionista?) (Origen. c. Cels. 7, 62-64). Amiano Marcelino, no quarto século EC, descreveu os Seres como pacíficos, "por não estarem

${ }^{7}$ A interpretação otimista de Dueck, 2012: 62, e a pessimista de Campbell, 2015, marcam os extremos opostos na literatura recente.

Heródoto, Unifesp, Guarulhos, v.4, n.1 - 2019.1. p. 395-422

DOI: 10.34024/herodoto.2019.v4.10128 
familiarizados com as armas e a guerra", e "incômodos para nenhum de seus vizinhos" (Amm. 23, 6, 67.). Plínio, citando uma fonte do Sri Lanka, afirmou que eles eram altos, com cabelos dourados e olhos azuis (Plin. $\mathrm{NH}$ 6, 24, 88. Cf. Sánchez Hernández, 2015:7).

Evidentemente, muitos dos dados coletados por esses (e outros) autores ocidentais não tinham sentido ou estavam simplesmente errados. Declarações igualmente desinformadas e relatos nebulosos sobre o Ocidente também podem ser encontrados nas fontes chinesas, como veremos a seguir. Uma escola de pensamento, portanto, sustenta que pouca ou nenhuma informação real passou de um grande império antigo para outro (Scheidel, 2009: 3; Campbell, 2015: 49; Fibiger Bang, 2009: 120; Loewe, 2010: 83). Portanto, surge a questão se existe alguma coisa em nossas fontes que sugira que a informação real ocasionalmente fluiu de um império para outro, ou se nossas fontes, como nos dias de Heródoto, continuam a transmitir histórias fantasiosas, diferindo apenas das anteriores por soarem mais "criveis". Em outras palavras, devemos aceitar que a literatura antiga sobrevivente reflete a extensão do conhecimento sobre a China antiga que estava disponível no Império Romano?

Talvez não. Pois a perda de textos do mundo romano é insondável, particularmente daqueles textos cujos autores e leitores eram de níveis sociais abaixo daqueles das elites imperiais. As obras perdidas, sem dúvida, incluíam não apenas textos como o Periplus Maris Erythraei, mas também toda a literatura de viagem, outrora abundante, que fornecia muitos dos dados subjacentes (De Romanis, 2016). É muito provável que pelo menos alguns desses textos tivessem transmitido visões mais informadas do Extremo Oriente, e que contivessem informações geográficas, topográficas, políticas, econômicas, culturais e outras mais precisas do que as encontradas nos escritos sobreviventes dos antigos geógrafos. O Periplus Maris Erythraei esclarece a natureza e a qualidade que os dados transmitidos por este ramo da literatura poderiam alcançar e, desse modo, dá uma ideia da extensão da perda. Pois, se este texto, que é transmitido apenas por um único manuscrito, tivesse compartilhado o destino do resto de seu gênero, seríamos privados da maior parte de nosso conhecimento atual sobre o comércio marítimo do século I entre Roma e Arábia do Sul, África Oriental e Índia, e de quase todos os detalhes que este texto único registra, pois quase nenhum dos dados ricos e superiores que ele contém podem ser encontrados em outro lugar. Portanto, parece prudente não tirar conclusões rígidas da suposição de que a literatura sobrevivente reflete quase tudo que já foi conhecido sobre a China antiga e o Extremo Oriente no mundo romano.

Heródoto, Unifesp, Guarulhos, v.4, n.1 - 2019.1. p. 395-422

DOI: 10.34024/herodoto.2019.v4.10128 


\section{Emissários e Mercadores}

Parece que os antigos textos historiográficos chineses começaram a se referir ao Império Romano no distante Ocidente durante o primeiro século EC (Leslie, Gardner, 1996; Pulleyblank, 1999; Hill, 2015). O termo que eles usaram foi "Da Qin”, "Grande China”, "aparentemente pensando nisso como uma espécie de contra-China no outro extremo do mundo", diz o grande sinólogo Edwin Pulleyblank (1999: 71-79. Cf. Ying, 2004: 327; Hoppál, 2011: 263-306; Yu, 2013: 1-128. Para outras noções do termo Da Qin, cf. Gizewski, Kolb, 1995: 488). Notavelmente, os primeiros textos chineses sobre Roma não contêm transcrições baseadas nos nomes Roma ou Imperium Romanum, o que ecoa a ausência paralela de um nome transcrito para a China nas fontes ocidentais mais antigas (Pulleyblank, 1999: 77. Contra cf. Gizewski, Kolb, 1995: 488). De qualquer forma, a existência do outro grande império foi doravante parte integrante do conceito do mundo habitado tanto na China imperial ("Da Qin") quanto no Império Romano ("Seres"). Além disso, havia agora um interesse considerável em ambos os lados do continente eurasiano em produzir relatos bem informados sobre esse outro império distante. O fluxo crescente de comércio ao longo dos vários ramos da "Rota da Seda" implicou um crescente fluxo de informações. Embora emissários e comerciantes possam ser identificados como portadores de informações relevantes, ainda é motivo de debate se alguma vez se estabeleceu contato direto entre Roma e China (Cf. Graf, 1992 e 2017; Leslie, Gardner, 1996; Hill, 2015; McLaughlin, 2010). Os contatos diplomáticos entre as principais potências ao longo do sistema de comércio da "Rota da Seda" são bem comprovados e incluem contatos chineses e romanos com representantes de vários países intermediários (Leslie, Gardner, 1996; Ziethen, 1994; Hill, 2015; McLaughlin, 2010; Arbach, Schiettecatte, 2015; Graf, 2017). Logo após a conquista romana do Egito, e sem dúvida como uma consequência direta das novas condições no extremo oeste das rotas de comércio de longa distância, fontes ocidentais relatam um surto de missões diplomáticas de países orientais de longe, alguns localizados na Índia e na Ásia Central, para o novo e único governante de Roma, Augusto. Dizem que chegaram a concluir acordos de "amizade" (amicitia) com ele e com o povo romano (Speidel, inédito, 2015, 2015). Infelizmente, nenhum desses acordos entre a Roma imperial e os distantes governantes orientais sobreviveu, mas a maioria deles foi, sem dúvida, concluída (escrita) em grego, já que essa língua serviu como língua franca para comerciantes e diplomatas em toda a Bacia do Mar Vermelho, Partia, Ásia Central e até a Índia (Strabo 15,1,73. Cf. Strabo 15,1,4. Dio 54,9,8.

Heródoto, Unifesp, Guarulhos, v.4, n.1 - 2019.1. p. 395-422

DOI: 10.34024/herodoto.2019.v4.10128 
Cf. Speidel, 2015: 112-119. Sobre o comércio romano de longa distância, cf. Raschke, 1978; Youg, 2001; Graf, 2017). No entanto, qualquer que tenha sido o conteúdo exato de tais acordos, a aparição de tantos emissários estrangeiros na corte de Augusto, após sua ascensão ao domínio exclusivo sobre o mundo romano, é um dos muitos exemplos reveladores do eficiente transporte de notícias feito pelos comerciantes de longa distância para seus respectivos centros políticos (Lee, 1993: 162-165 e 175-177; Austin, Rankov, 1995: 26-28, 87-88, 94, 100, 210). Tais informações poderiam, então, ser transferidas para documentos escritos, mais desenvolvidas ou condensadas, armazenadas e recuperadas para servir de base para conclusões e decisões políticas, fiscais ou militares. O mesmo é, evidentemente, verdadeiro para a informação que foi oficialmente, e secretamente, coletada e transportada por emissários oficiais (Hdt. 3, 17. Plut. Alex. 5, 1. Lee, 1993: 166-170. Austin, Rankov, 1995: 120-123). Sabemos, até mesmo, de missões inteiras que a Roma imperial ocasionalmente montou e enviou para coletar informações sobre países estrangeiros distantes (Sen., Q. nat. 6, 8, 3. Plin. NH 6,35,181. 184-186. 12, 8, 19. Dio 63, 8, 1. Cf. Austin, Rankov, 1995: 114-118; Lee, 1993: 170-182).

$\mathrm{O}$ registro de enviados estrangeiros para Augusto inclui um grupo de chineses. Esta missão é conhecida através de um único autor romano, Floro (do início do segundo século EC), que observa a chegada à corte de Augusto de enviados dos Seres (Florus 2, 34.). O relato de Floro associa os emissários chineses com indianos "que vivem imediatamente abaixo do sol. Embora trouxessem elefantes entre seus presentes, bem como pedras preciosas e pérolas, consideravam sua longa jornada, que levou quatro anos, como sua maior homenagem. E, de fato, sua aparência provou que eles vieram de outro céu". Floro não deixa claro se os chineses, dos quais ele não tem mais nada a dizer, chegaram junto com os indianos e como se comunicavam com os romanos. No entanto, o testemunho de Floro é geralmente rejeitado, pois nem mesmo o capítulo sobre embaixadas estrangeiras nas res gestae de Augusto menciona enviados dos Seres. Esperaríamos, de fato, que Augustus o fizesse, já que os governantes romanos nunca hesitaram em interpretar, aceitar e promulgar quaisquer visitas como sinais de submissão (Cf. Ferguson, 1978: 592-593; Poinsotte, 1979: 435; Ziethen, 1994: 189-192). O próximo esforço chinês registrado de estabelecer contato direto com a Roma imperial ocorreu aproximadamente um século depois. De acordo com um relato chinês, em 97 EC, o general Ban Chao enviou seu principal embaixador, Gan Ying, em uma missão para estabelecer contato com Da Qin. O contexto geral parece ter sido militar, mas a missão fracassou porque os partos a frustraram, supostamente porque temiam perder o controle do comércio de seda por

Heródoto, Unifesp, Guarulhos, v.4, n.1 - 2019.1. p. 395-422

DOI: 10.34024/herodoto.2019.v4.10128 
terra (Hou Hanshu 88 (Hill, 2004: sect. 10 e 12; Hill, 2015, vol. I: 23 e 27). De qualquer modo, embora Gan Ying nunca tenha realmente alcançado o Imperium Romanum, é dito que ele chegou às praias do Golfo Pérsico em 97 EC, onde ele certamente coletou tantas informações sobre Da Qin quanto pôde (sobre a missão e o debate sobre o itinerário de Gan Ying, cf. Hou Hanshu 88 (Hill, 2004: sect. 10; Hill, 2015, vol. I: 23), Hill, 2015: 16-20; Leslie, Gardner, 1996: 141-148; Hoppál, 2011: 299-300; Yu: 2013: 5, 10-17).

Vários contatos romanos diretos com os chineses também estão registrados. O geógrafo Marino de Tiro, por exemplo, referiu-se a um relato do século I de um comerciante desconhecido da Macedônia romana chamado tanto de Maës quanto Titianus, que usou as informações fornecidas por seus agentes e libertos para observar os tempos de viagem e as distâncias ao longo da rota que levava de uma estação comercial no Pamirs (a "Torre de Pedra") para "Sera", a capital do Seres. Infelizmente, tanto o registro de Maës quanto o de Marino estão perdidos. Só se sabe que existiram porque o geógrafo alexandrino Claudio Ptolomeu os menciona em um parágrafo curto em sua Geografia, na qual ele cita Maës como sua fonte para a alegação (na qual ele e Marino não acreditam) de que era uma viagem de sete meses entre a "Torre de Pedra" até "Sera", a capital do Seres (Ptol. 1,11. Cf. Ptol. 1.12.1-10. Heil, Schulz, 2015. Ainda há especulações sobre se a jornada foi relatada em fontes chinesas, cf. Leslie, Gardner, 1996: 149; McLaughlin, 2010: 126-128) ${ }^{8}$. Foi precisamente esta rota, passando pela "Torre de Pedra" para a terra dos Seres, que Amiano Marcelino qualificou, mais tarde, como iter longissimum e que ele relata que foi "frequentemente" ou "periodicamente" usada pelos mercadores no quarto século CE".

De acordo com antigos textos chineses, a primeira "embaixada" romana a visitar a China só chegou em 166 EC, e veio do Sul (via a rota marítima do Mar Vermelho e do Oceano Índico) (Hou Hanshu 88 (Hill, 2004: sect. 12; Hill, 2015, vol. I: 27), McLaughlin, 2010: 133; Schulz, 2016: 389). Os chineses registraram a chegada de "emissários" do imperador romano Āndūn (ou seja, Marco Aurélio, ou, talvez, Antonino Pio) na corte chinesa, com ofertas de chifres de rinoceronte, marfim e cascos de tartaruga. Os chineses, naturalmente, levaram esses presentes como tributos, mas, tendo esperado joias e exotismo do rei de Da Qin, eles não ficaram impressionados e começaram a suspeitar que os relatos maravilhosos que tinham ouvido

\footnotetext{
8 O local identificado como "Torre de Pedra" é, na maioria das vezes, identificado como Taškurgan ou Darautkurgan, cf. Poinsotte, 1979: 445, Paul, 2005: 955. A metrópole de "Sera" permanece sem identificação.

9 De acordo com Campbell, 1989: 372, Amiano Marcelino, nessa passagem, estava apenas exibindo o conhecimento que extraiu de Ptolomeu.
}

Heródoto, Unifesp, Guarulhos, v.4, n.1 - 2019.1. p. 395-422

DOI: 10.34024/herodoto.2019.v4.10128 
sobre o Império Romano eram totalmente exagerados (Leslie, Gardner, 1996: 223; Hill, 2015: 307-308). Pois, no mundo antigo, o valor local dos bens importados refletia diretamente na reputação de seu país de origem, bem como no significado de seus governantes ${ }^{10}$. Éduard Chavannes, em 1907, argumentava, portanto, que os "enviados" romanos eram de fato comerciantes romanos (Chavannes, 1907: 185; Wheeler, 1954: 174. Cf. Loewe: 2010: 83; Fibiger Bang, 2009: 120). Se o episódio é baseado em um encontro real, Chavannes é, claramente, a solução mais atraente, embora a questão de como as duas partes se comunicaram permaneça sem solução (Hill, 2015: 308; McLaughlin, 2010: 133-135; Feng, 2013: 281-282). É difícil imaginar a partir de qual outro grupo profissional os "emissários" oficiais do imperador romano para o distante governante dos Seres poderia ter se originado. De qualquer forma, provavelmente deveríamos supor que os "emissários" romanos eram, geralmente, cidadãos romanos nascidos livres, mas a história do cavaleiro romano que viajou 600 milhas através da Germânia até as margens do Mar Báltico para comprar âmbar durante o reinado de Nero (54-68 EC) mostra que nem todos os mercadores de longa distância eram necessariamente de status social modesto. Além disso, as autoridades romanas também são conhecidas por terem confiado aos comerciantes estrangeiros a entrega de mensagens para destinatários distantes ${ }^{11}$. No entanto, não há registro da embaixada de 166 EC em fontes ocidentais, e nem todos os estudiosos acreditam em sua historicidade ${ }^{12}$.

Os chineses registraram o contato de 166 EC como "a primeira vez que houve comunicação [direta]" (isto é, entre os dois impérios). Isso parece implicar que várias outras visitas se seguiram, mas apenas dois outros contatos diretos estão registrados no terceiro século, ambos conhecidos apenas por meio de fontes chinesas e ambos referentes a visitantes romanos à China. Assim, um relato chinês do século VI, usando material de períodos muito anteriores (Liang-Shu, 54), relata a visita, em 226 EC, de um comerciante romano à corte do rei de $\mathrm{Wu}$ (o posterior imperador de $\mathrm{Wu}$ ), Sun Quan, em Nanquim. Supostamente, esse mercador (chamado Qin Lun nos textos chineses), que parece ter chegado pela rota marítima, deixou um relato detalhado do Império Romano, agora perdido, com Sun Quan (Leslie, Gardner, 1996: 100-101 e 158-159. Cf. Hirth, 1885: 46-48;

\footnotetext{
10 Para o comentário romano, cf. Tac., Ann. 2,60. Sri Lanka, cf. Plin., NH 6, 24, 85 e Cosmas 11, 338. China, cf. Hou Hanshu 88 (Hill, 2004: sect. 12, Hill, 2015, vol. I: 27).

${ }_{11}$ Cavaleiro romano: Plin. NH 37, 11, 45. Mercadores estrangeiros: Tac., Ann. 14, 25. Cf. Hillers, Cussini, 1995: 2754.

12 Campbell, 1989: 373, argumenta: "comentadores presumem, ingenuamente, que o anterior [ou seja, o nome An-Tun] é o equivalente fonético de [Marco] Antonino". Campbell, 2015: 49: "Marco Antonino ... tem apenas uma leve semelhança com "AnTun"'".
}

Heródoto, Unifesp, Guarulhos, v.4, n.1 - 2019.1. p. 395-422

DOI: 10.34024/herodoto.2019.v4.10128 
McLaughlin, 2010: 136) ${ }^{13}$. Novamente, nada é dito sobre como a comunicação foi estabelecida e como a linguagem ou a tradução possivelmente afetaram as informações registradas. Em 284/85 EC, outra "embaixada" romana trazendo "tributo" (incluindo, aparentemente, amianto) é registrada em outras fontes chinesas como tendo chegado à China (provavelmente através da rota marítima) (Leslie, Gardner, 1996: 159-160). Nenhum outro detalhe parece ser conhecido. Assim, as fontes existentes, com exceção de Amiano Marcelino, não implicam muita interação direta entre os dois grandes impérios nos extremos opostos do continente euro-asiático durante os primeiros três séculos EC. Na verdade, o relato que registra a visita de 226 EC (Liang-Shu, 54) afirma explicitamente que os mercadores romanos frequentemente visitavam Funan (Camboja), Jih-nan (Annam) e Chiao-chih (Tongking), mas raramente viajavam para China. Isso vai de encontro com a afirmação do Periplus Maris Erythraei (PME 64) de que "raramente as pessoas vêm dele [isto é, "Thina" / China], e apenas alguns ". Assim, geralmente se considera que os comerciantes não percorreram toda a rota de leste para oeste ou vice-versa, mas que o comércio de longa distância foi organizado por etapas e envolveu vários intermediários (Ying, 2004; Ruffing, 2014; Sánchez Hernández, 2015; Graf, 2017).

No entanto, talvez não se deva excluir, a priori, a possibilidade de que alguns indivíduos realmente viajaram toda a distância, ou partes muito substanciais dela (Ruffing, 2014: 73). A história de Maës, bem como a referência de Amiano Marcelino à longa estrada que leva ao "Povo da Seda" e à afirmação de Liang-Shu de que mercadores romanos navegaram até a Birmânia moderna, Camboja e Vietnã, mas raramente até a China, todos parecem implicar a existência de um pequeno grupo de indivíduos que, ocasionalmente, percorriam longas distâncias entre os dois reinos imperiais. Mais importante, no entanto, aparentemente havia uma vontade e uma ampla oportunidade de se encontrar em algum lugar do caminho entre os impérios. Assim, a missão de Ban Chao foi explicitamente registrada como tendo tentado estabelecer contato direto com Da Qin. Mesmo que seu enviado, Gan Ying, nunca tenha realmente alcançado o Imperium Romanum, ele teria chegado às margens do Golfo Pérsico em 97 EC, onde deve ter tido a oportunidade de coletar muitas informações sobre Da Qin. No entanto, em vez de descobrir caminhos viáveis para as fronteiras do Império Romano, Gan Ying deixou-se desencorajar por histórias de uma passagem marítima horrenda e potencialmente mortal, contadas por "marinheiros da fronteira ocidental da Pártia", e voltou para

${ }^{13}$ Este relato não parece ser a fonte de informação utilizada pelo Weilüe, já que este texto se ocupa exclusivamente da rota terrestre.

Heródoto, Unifesp, Guarulhos, v.4, n.1 - 2019.1. p. 395-422

DOI: 10.34024/herodoto.2019.v4.10128 
casa (Hou Hanshu 88 (Hill, 2004: sect. 10; Hill, 2015, vol. I: 23), Leslie, Gardner, 1996: 46). Mas Gan Ying não foi o único chinês a alcançar a Pártia durante a dinastia Han.

A Pártia tinha contato diplomático e comercial com ambos os impérios ${ }^{14}$. Portanto, não é improvável que, apesar das reivindicações chinesas de tentativas partas de impedir o contato direto, a Pártia oferecesse oportunidades para indivíduos de ambos os lados do continente eurasiano se reunirem, já que não há evidências que sugiram um bloqueio total e permanente da rota terrestre através da Pártia para comerciantes romanos ${ }^{15}$. O Oásis de Merv (Antioquia / Alexandria em Margiana), em particular, pode ter sido um lugar onde os comerciantes de ambos os impérios se encontravam recorrentemente (Hou Hanshu 88 (Hill, 2004: sect. 11; Hill, 2015, vol. I: 23, 248-249) Plin. NH 6, 18, 46-47. Isid. Char. 14. Cf. Graf, 2017. Coloru, Traina, Lycas, 2016: 49-58). Mais oportunidades de contato direto repetido também podem ter ocorrido em outros mercados intermediários da Índia, do centro e sudeste asiáticos ou Arábia do Sul (Cf. Lewis, 2007: 143; Fauconnier, 2012; Feng, 2013: 279). Se isto é verdade, isto tem grande importância, pois dentro das sociedades pré-industriais os mercados desempenham um papel crucial e notório na circulação e disseminação da informação (Cf. Lee, 1993: 175-177; Austin, Rankov, 1995: 27, 209-210). Sem dúvida, as informações assim coletadas e trazidas de volta aos impérios romano e chinês por mercadores e emissários, poderiam, eventualmente, chegar em documentos que estavam à disposição daqueles que tomavam decisões imperiais. O geógrafo alexandrino Ptolomeu, por exemplo, citando o relato de Marino da jornada dos agentes de Titianus até a Ásia Central, reconheceu explicitamente que "tudo isso se tornou conhecido por meio de uma oportunidade proporcionada pelo comércio" (Ptol. 1,11). Além disso, Étienne de la Vaissière recentemente argumentou de forma convincente que a descrição de Ptolomeu da bacia de Tarim, em sua Geografia, é baseada em três diferentes itinerários comerciais, que ele usou como fontes para sua representação da Ásia Central e, especialmente, de Xinjiang (De la Vaissière, 2009). Tudo isso destaca a extensão pela qual

\footnotetext{
14 Sobre embaixadas para e da China, cf. Hou Hanshu 88 (Hill, 2004: sect. 10, Hill, 2015, vol. I: 23), Leslie, Gardner, 1996: 46 e 139-143.

${ }_{15}$ Contato frustrado: Hou Hanshu 88 (Hill, 2004: sect. 12, Hill, 2015, vol. I: 27) e Leslie, Gardner, 1996: 51. Weilüe: 11 (Hill, 2004: sect. 11) e Leslie, Gardner, 1996: 70. Cf. Hirth, 1885: 42. Bloqueio: Mansiones Parthicae, de Isidor de Charax, o relato de Ptolomeu da jornada do agente de Maës Titianus (1,11), e a Tabula Peutingeriana sugerem que a passagem era possível (pelo menos, as vezes). Graf, 2017, contra Walter, 2009:113. De forma geral, entretanto, as evidências sugerem que os mercadores romanos preferiam a rota marítima, talvez pelas condições desfavoráveis aos mercadores romanos na Pártia.
}

Heródoto, Unifesp, Guarulhos, v.4, n.1 - 2019.1. p. 395-422 
a natureza e limitações das evidências ocidentais se devem ao material escrito produzido por comerciantes de longa distância.

\section{Dados Chineses}

Infelizmente, todos os registros oficiais do mundo romano que poderiam conter informações sobre povos e países estrangeiros se desintegraram. É, portanto, particularmente afortunado que alguns registros antigos com informações "oficiais" sobre o outro tenham sobrevivido na China ${ }^{16}$. Estes documentos oferecem uma oportunidade única para estudar a transmissão de informações de Roma para a China. Desde que Friedrich Hirth, em 1885, publicou sua monografia China and the Roman Orient com uma seleção de textos chineses antigos contendo informações sobre os impérios romano e bizantino (incluindo traduções e comentários extensos), esses registros atraíram a atenção dos estudiosos, embora, até recentemente, principalmente entre os Sinologistas (Hirth, 1885) ${ }^{17}$. O registro do interesse chinês sobre o Império Romano não é, em geral, diferente do interesse romano sobre a China. Os textos orientais fornecem informações sobre as rotas e a comunicação com Da Qin e outras "Regiões Ocidentais", sobre sua geografia, sua capital, sua administração e infraestrutura, sobre reinos dependentes, sobre sua agricultura e pecuária, sobre têxteis, perfumes e ervas, e sobre outros recursos naturais, bem como sobre a população e sua aparência e vida cotidiana. Claramente, portanto, os dados transmitidos por esses textos precisam ser verificados em relação ao que se sabe sobre o mundo imperial romano a partir de fontes ocidentais, se quisermos estabelecer o valor da informação sobre Da Qin que foi registrada nos antigos registros chineses.

Dois textos em particular precisam ser mencionados, o Hou Hanshu e o Weilüe. Pesquisas recentes descrevem-nos da seguinte forma (Hill, 2015, vol. I: xvi - xxiii; Mansvelt Beck, 1990: 1; Bielenstein, 1953: 16-17). O Hou Hanshu é a história oficial da Dinastia Han posterior (ou "Oriental") (25221 EC). Foi compilado principalmente por um homem chamado Fan Ye, na primeira metade do quinto século EC, a partir de trabalhos anteriores.

\footnotetext{
16 Traduções estão, convenientemente, a mão: cf. Hirth, 1885, Leslie, Gardner, 1996, Hill, 2004 e 2015. Os presentes autores trabalharam exclusivamente com traduções dos textos chineses. Nós nos sentimos justificados neste trabalho porque as observações apresentadas nesta contribuição são baseadas, primariamente, na essência de passagens em que a tradução parece estar correta. Citações são das traduções de John Hill.

17 Para bibliografia, cf. Leslie, Gardner, 1996: 3-6, Hill, 2015, Hoppál, 2011: 266-269, Yu, 2013: 43-127. Ver também Kordosis, 1991, Naerebout, 1996, Gizewski, Kolb, 1995. Para importantes comentários de um historiador, cf. Graf, 2017.
}

Heródoto, Unifesp, Guarulhos, v.4, n.1 - 2019.1. p. 395-422

DOI: 10.34024/herodoto.2019.v4.10128 
Ele contém seções sobre as "Regiões Ocidentais" que são baseadas principalmente em um relatório de Ban Yong (o filho de Ban Chao) ao imperador An em c. 125 EC e substituíram os relatos anteriores (Hou Hanshu 88 (Hill, 2004: sect. 1; Hill, 2015, vol. I: 13, cf. 161-163). Este relatório incluiu descrições do Império Romano que se originaram da informação que o enviado de Ban Chao, Gan Ying, coletou durante sua missão a Da Qin em 97 EC. O outro texto historiográfico inicial que contém informações importantes sobre Da Qin, o Weilüe, é um capítulo sobre "Povos do Ocidente" de um "Breve relato da dinastia Wei", agora perdido, compilado em uma data desconhecida no terceiro século EC por Yu Huan (Chavannes, 1905: 519-571; Leslie, Gardner, 1996: 65-68; Hill, 2004; Hoppál, 2011: 268269). O capítulo sobreviveu como uma extensa citação em uma obra do século V. Ele repete informações anteriores sobre Da Qin (incluindo muito do que pode ser encontrado no Hou Hanshu) e também fornece material novo valioso, que parece datar principalmente do século II e do início do século III EC18.

Em suma, estes textos são, pelo menos em parte, de natureza verdadeiramente oficial e decorrem de um período contemporâneo a existência do Imperium Romanum. No entanto, vários problemas estão relacionados com os relatos históricos chineses e sua interpretação, e não há consenso sobre quanta informação real sobre o Império Romano eles realmente contêm ${ }^{19}$. A compilação desses textos na China antiga era um procedimento burocrático que envolvia muitas cópias de relatos anteriores e contava com registros e arquivos (Cf. Loewe, 1986: 2-6 e 2010: 75-77; Leslie, Gardner, 1996: 19-31; Hoppál, 2011: 269). Assim, as origens e a data precisas das informações originais subjacentes permanecem desconhecidas. De qualquer forma, a natureza específica desses textos aparentemente reflete o que era, oficialmente, considerado verdadeiro no momento de sua redação (o que, é claro, não exclui a possibilidade de que outros conhecimentos do Ocidente existissem simultaneamente). É interessante, portanto, que o Hou Hanshu tenha caracterizado os romanos como "honestos nos negócios: eles não têm dois preços", pois isso parece indicar que o interesse chinês no povo de Da Qin era, primariamente, motivado pelo comércio (Hou Hanshu 88 (Hill, 2004: sect. 12; Hill, 2015, vol. I: 27), Ying, 2004: 339). O Liang-Shu (54) até mesmo caracterizou os habitantes de Da Qin como um povo comercial (Leslie, Gardner, 1996: 100). O comércio de longa distância é de fato um tópico muito proeminente e recorrente nos

18 Para outras fontes (posteriores) chinesas relevantes sobre o mundo mediterrâneo, ver Leslie, Gardner, 1996: 3, 33, 57 e 80. Cf. Hoppál, 2011: 268-269.

${ }^{19}$ Ver as visões contraditórias em Kordosis, 1991, Naerebout, 1996, ou Gizewski, Kolb, 1995.

Heródoto, Unifesp, Guarulhos, v.4, n.1 - 2019.1. p. 395-422

DOI: 10.34024/herodoto.2019.v4.10128 
relatos históricos chineses do ocidente distante. Em particular, longas listas de bens desejáveis são características da descrição de Da Qin no Hou Hanshu e ainda mais no Weilüe, já que listas similares não parecem se repetir com a descrição de outros países ocidentais nesses textos (Hou Hanshu 88 (Hill, 2004: sect. 12; Hill, 2015, vol. I: 25), Weilüe 12 (Hill, 2004: sect. 12). Assim, eles são uma evidência clara do interesse comercial muito pronunciado dos chineses em Da Qin. Além disso, esses textos caracterizam o comércio de longa distância romano e chinês (ao qual eles aparentemente se referem como "comunicação" entre países) como um assunto essencialmente "nacional", no qual a diplomacia abre rotas comerciais e mercados $^{20}$. Talvez isto não deva, simplesmente, ser tomado como uma representação especificamente chinesa do comércio transnacional, pois as fontes romanas também implicam que a diplomacia e os acordos internacionais estavam envolvidos na facilitação do comércio de longa distância (Speidel, 2015 e inédito).

O Hou Hanshu e o Weilüe descrevem Da Qin como um estado grande (e, por implicação, poderoso) com muitas dependências (Hou Hanshu 88 (Hill, 2004: sect. 11; Hill, 2015, vol. I: 23), Weilüe 11 e 14 (Hill, 2004: sect. 11 e 14)). Eles elogiam seus habitantes como "altos e honestos" (Hou Hanshu 88 (Hill, 2004: sect. 11; Hill, 2015, vol. I: 25)), mas não têm nada a dizer sobre suas forças armadas ou seus sucessos no campo de batalha. Não há descrições do exército, da capacidade militar ou marcial de Roma (Leslie, Gardner, 1996: 260). Dado o interesse geral dos chineses em assuntos militares, isso talvez seja surpreendente, uma vez que a China tinha contato ocasional, mas direto, com os partos, que estiveram em guerra com os romanos em várias ocasiões. Talvez os informantes partas não estivessem dispostos a fornecer aos chineses tal informação. De qualquer forma, os Hou Hanshu e os Weilüe retratam os romanos como um povo pacífico e justo, diferente das descrições dos chineses em alguns antigos textos ocidentais. Apesar das tentativas chinesas de coletar informações precisas e reais sobre os romanos e seu império, até mesmo o termo "Da Qin" está na raiz de vários problemas interpretativos. As concepções chinesas de Da Qin foram "confundidas desde o início com antigas noções mitológicas" de um império utópico no Extremo Oeste (Laufer, 1913; Graf, 1992: 199-216, esp. 199-200; Pulleybank, 1999: 78; Hoppál, 2011: 264; Yu, 2013: 69-70; Walter,

\footnotetext{
${ }^{20}$ Hou Hanshu 88 (Hill, 2004: sect. 12, Hill, 2015, vol. I: 27): “O rei deste país [Roma] sempre quis enviar emissários para Han [China\}, mas Anxi [Pártia], desejando controlar o comércio das sedas multicoloridas chineses, bloqueou a rota para impedir [os romanos] de passarem [até a China]. Hou Hanshu 88 (Hill, 2004: sect. 15, Hill, 2015, vol. I: 31): "Esta região [o noroeste da Índia] ... se comunica com Da Qin". Weilüe 12 (Hill, 2004: sect. 12): "Por isso, este país [Roma] negocia com Anxi [Pártia]".
}

Heródoto, Unifesp, Guarulhos, v.4, n.1 - 2019.1. p. 395-422

DOI: 10.34024/herodoto.2019.v4.10128 
2009: 116-117). Tais noções estavam nas origens do termo "Da Qin", pois significava literalmente "Grande China" e não era uma transcrição de um nome estrangeiro para o Império Romano (Pulleybank, 1999: 71 e 77; Hill, 2015, vol. I: 266-271; Hoppál, 2011: 269-271; Yu, 2013: 1-43, Cf. Naerebout, 1996; Gizewski, Kolb, 1995). Além disso, a existência de uma "Grande China" no extremo oposto do mundo entrava em conflito com a antiga concepção chinesa do mundo real, segundo a qual a China (o "Reino do Meio") era o seu centro cultural. De acordo com essa concepção, quanto mais longe um estrangeiro vivia do centro, mais "bárbaro" acreditava-se que ele era (Cf. Creel, 1929; Wang, 1999: 285-305). Mas é claro que era impensável que o povo da "Grande China" fosse o povo mais incivilizado do mundo. Portanto, eles foram retratados como parecidos com "o povo do Reino do Meio, e é por isso que esse reino é chamado Da Qin" (Hou Hanshu 88 (Hill, 2004: sect. 11; Hill, 2015, vol. I: 23)). Os romanos eram descritos como "altos e virtuosos como os chineses, mas usam roupas ocidentais". Uma explicação também foi fornecida: "Eles [os romanos] dizem que originalmente vieram da China, mas a deixaram" (Weilüe 11 (Hill, 2004: sect. 11), Leslie, Gardner, 1996: 70. Cf. Hill, 2015, vol. I: 267). É evidente, portanto, que tais noções utópicas e fantasiosas de Da Qin se originaram na China e precisam ser identificadas se quisermos investigar a extensão da informação real que chegou à China sobre o Oeste.

Outra questão particularmente complexa, que também afeta nossa compreensão do termo "Da Qin", diz respeito às notórias dificuldades em identificar características topográficas e geográficas nos antigos registros chineses ${ }^{21}$. A principal dificuldade é que a transcrição de nomes de lugares estrangeiros a partir de caracteres chineses, e a reconstrução de seus valores fonológicos no período Han, exige um conhecimento altamente especializado da fonologia histórica chinesa e, aparentemente, muitas vezes produz resultados altamente controversos. Além disso, não é geralmente levado em conta que muitos lugares no Oriente Romano, em particular, tinham mais de um nome (dependendo principalmente do tempo e da língua: por exemplo Yerushalaim, Hierosolyma, colônia Aelia Capitolina e Iliya, para mencionar apenas alguns antigos nomes de Jerusalém), e que os autores chineses podem ter transcrito pronúncias de nomes de lugares que a (múltipla) transmissão por falantes não-gregos e não-latinos haviam distorcido significativamente. A questão é claramente importante se quisermos entender e fazer uso desses textos. A introdução do capítulo sobre o Império Romano no Hou Hanshu pode servir de ilustração: "O Reino de Da Qin também é chamado de Lijian. Como é

21 Sobre esta questão, de modo geral, ver Pulleybank, 1999, Hill, 2015, vol. I: xx-xxiii. Cf. Kordosis, 1991, Naerebout, 1996: 375-376, ou Gizewski, Kolb, 1995: 487-489.

Heródoto, Unifesp, Guarulhos, v.4, n.1 - 2019.1. p. 395-422

DOI: 10.34024/herodoto.2019.v4.10128 
encontrado a oeste do mar, é também chamado de Reino de Haixi [="Oeste do Mar"]" (Hou Hanshu 88 (Hill, 2004: sect. 11; Hill, 2015, vol. I: 23)). Quase a mesma declaração também foi incluída no Weilüe ${ }^{22}$. Talvez não seja inteiramente surpreendente que o lendário império da "Grande China", como um estado real, também tivesse outros nomes menos míticos, derivados de entidades políticas ou geográficas existentes. No entanto, não há consenso sobre a quais países ou regiões Lijian e Haixi se referem e, portanto, ainda permanece incerto qual parte o termo "Da Qin" indicava exatamente. Assim, a equação de Da Qin, Lijian e Haixi, bem como outras tentativas de identificar nomes de lugares nas seções dos antigos registros chineses sobre Da Qin, levou a um debate confuso e ainda em andamento, no qual, no entanto, o número de opções em discussão não parece ter mudado muito desde as estabelecidas por Friedrich Hirth e seus sucessores imediatos. Essencialmente, as soluções propostas para o significado de " $\mathrm{Da}$ Qin" como um local existente são o Império Romano, as regiões orientais do Império (como já sugerido por Friedrich Hirth), particularmente a Síria e o Egito, a península arábica ou coisas completamente diferentes dependendo no contexto da narrativa (Laufer, 1913; Weller, 1927; Kordosis, 1991. Cf. Leslie, Gardner, 1996: xxi-xxvi e 232; Hill, 2015, vol. I: 266-271; Hoppál, 2011: 269-271; Yu, 2013: 1-42).

Tanta confusão e tantas interpretações contraditórias por especialistas dos campos relevantes da Sinologia podem desencorajar estudiosos do antigo mundo mediterrâneo a fazer uso dos antigos relatos chineses do ocidente distante (Naerebout, 1996: 376; Fibiger Bang, 2009:120). Ainda assim, talvez haja uma abordagem que leve a resultados mais confiáveis (Kolb, Speidel, 2015: 137ff). O contexto implica que o que quer que seja que os termos "Lijian" e "Haixi" referenciavam, eles não eram totalmente sinônimos de "Da Qin", mas partes ou aspectos designados dele. Isto é, por exemplo, sugerido por declarações, registradas no Hou Hanshu, sustentando que a pessoa entra "em Haixi para alcançar Da Qin" ou que "nestes territórios [de Da Qin], há muitas coisas preciosas e maravilhosas de Haixi" (Hou Hanshu 88 (Hill, 2004: sect. 12; Hill, 2015, vol. I: 27), cf. Leslie, Gardner, 1996: 52. Hou Hanshu 88 (Hill, 2004: sect. 10; Hill, 2015, vol. I: 23), cf. Leslie, Gardner, 1996: 47). Outra passagem, de um capítulo diferente do Hou Hanshu, menciona um grupo de músicos e mágicos, em 121 EC, que alegou ser de Haixi, e que o chinês responsável pelo registro identificou como Da Qin (Leslie, Gardner, 1996: 42; Pulleybank, 1999: 75; Hill, 2015, vol. I: 306. Cf. Hoppál, 2011: 270; Yu, 2013: 22). Curiosamente, o termo "Lijian" não se repete nas seções sobre Da Qin do Hou Hanshu ou do Weilüe. Haixi é o

22 Weilüe 11 (Hill, 2004: sect. 11): “O reino de Da Qin também é chamado Lijian. Fica a oeste de Anxi [Pártia] e Tiaozhi, e a oeste do Grande Mar". Cf. Leslie, Gardner, 1996: 67.

Heródoto, Unifesp, Guarulhos, v.4, n.1 - 2019.1. p. 395-422

DOI: 10.34024/herodoto.2019.v4.10128 
único aspecto geográfico concreto de Da Qin que esses textos especificam. John E. Hill recentemente argumentou, de forma convincente, que "Haixi", como parte de "Da Qin", refere-se ao Egito, principalmente porque está de acordo com a localização geográfica ("Oeste do Mar"), com as distâncias (da Pártia, em particular) e com a característica topográfica mais proeminente do país, dada pelas antigas fontes chinesas (um rio que desemboca em outro grande mar), e, também, porque, aparentemente, fornece uma representação fonética razoável do nome grego do país, Aigyptos (Hill, 2015, vol. I: 263-266) ${ }^{23}$.

Um olhar mais atento às passagens do Hou Hanshu e do Weilüe descrevendo o governo de Da Qin / Lijian / Haixi sugere que eles não estão lidando com o Império Romano em sua totalidade. Nos registros de Hou Hanshu: "Seus reis não são permanentes. Eles selecionam e nomeiam o homem mais digno. Se houver calamidades inesperadas no reino, como frequentes ventos ou chuvas extraordinárias, ele é rejeitado e substituído sem a menor cerimônia. Aquele que foi dispensado silenciosamente aceita seu rebaixamento e não fica zangado" (Hou Hanshu 88 (Hill, 2004: sect. 11; Hill, 2015, vol. I: 25). Cf. Leslie, Gardner, 1996: 49). A passagem equivalente no Weilüe diz: “O governante deste país (a referência parece ser para Haixi) não é permanente. Quando os desastres resultam de fenômenos incomuns, eles o substituem sem cerimônia, instalando um homem virtuoso como rei e libertam o velho rei, que não ousa mostrar ressentimento" (Weilüe 11 (Hill, 2004: sect. 11). Cf. Leslie, Gardner, 1996: 70) ${ }^{24}$. Esta declaração é, alternadamente, pensada como uma referência à prática imperial do segundo século EC de nomear um sucessor ao trono pela adoção (o Adoptivkaisertum), ao sistema republicano de cônsules eleitos, aos governos provinciais romanos do quarto ao sétimo séculos EC no Oriente ou, ainda, ser nada mais do que uma história fantasiosa de um país ideal distante (Ferguson, 1978: 593; Kordosis, 1991: 160ff; Gizewski, Kolb, 1995: 487; Leslie, Gardner, 1996: 49; Hill, 2004: notas 11.18; Hoppál, 2011: 276-282; Yu, 2013: 619). No entanto, outras partes da mesma passagem sugerem uma solução diferente. Nestes, diz-se que o rei deixou seu palácio regularmente para ouvir casos e, de acordo com o Hou Hanshu: "um porteiro com uma bolsa tem o trabalho de sempre seguir a carruagem real. Quando alguém

\footnotetext{
23 Hoppál, 2011: 276-282, argumenta, de forma ampla, pela identidade menos convincente de Haixi com as cidades de Roma ou a Antioquia Síria, mas concluí (p. 282) que "é mais provável que os chineses não possuíssem informações sobre a extensão exata e o sistema político do Império Romano" e que "Da Qin se referia a diferentes coisas, dependendo do contexto".

${ }^{24}$ A mesma declaração pode ser encontrada no Hou Hanchi e no Chinshu. Leslie, Gardner, 1996: 61 e 81.
}

Heródoto, Unifesp, Guarulhos, v.4, n.1 - 2019.1. p. 395-422

DOI: 10.34024/herodoto.2019.v4.10128 
quer discutir algo com o rei, ele atira uma nota na bolsa. Quando o rei retorna ao palácio, ele abre a bolsa, examina o conteúdo e julga se o autor está certo ou errado" (Hou Hanshu 88 (Hill, 2004: sect. 11; Hill, 2015, vol. I: 25), cf. Leslie, Gardner, 1996: 48). A passagem paralela no Weilüe diz: "Quando o rei saí, ele sempre manda um homem segui-lo segurando uma bolsa de couro. Qualquer um que tenha algo a dizer lança sua petição na bolsa. Quando ele [o rei] retorna ao palácio, examina-os e determina quais são razoáveis" (Weilüe 11 (Hill, 2004: sect. 11). Cf. Leslie, Gardner, 1996: 71) ${ }^{25}$. As mesmas passagens, em ambos os textos, também contêm referências a arquivos governamentais e a um grupo de conselheiros.

É muito tentador entender esses comentários não como fantasias de domínio imperial, mas como referências baseadas em fatos ao governo provincial romano. É muito tentador entender esses comentários não como fantasias de domínio imperial, mas como referências baseadas em fatos ao governo provincial romano. Pois não é difícil reconhecer uma descrição detalhada dos aspectos centrais dos deveres de um governador provincial: a viagem de ida e volta através de seus casos de audiência na província, o conhecido sistema de coletar petições, preparar respostas e fazer uso de arquivos, bem como discutir assuntos de estado com seu consilium. Consequentemente, a primeira citação relativa à substituição de reis talvez não se refira, tampouco, a reis verdadeiros. Em vez disso, transmitindo a noção de que o país não tinha um governante permanente, mas um sistema (que os chineses que o registraram não entendiam completamente) pelo qual homens "dignos" e "virtuosos" foram selecionados para substituir seus predecessores, esses textos chineses antigos novamente parecem referir-se ao governo provincial romano. Isto, de qualquer forma, vai de encontro à proposta de John Hill de que o "Haixi" do Hou Hanshu e do Weilüe se refere ao Egito. Pode-se objetar que os relatos chineses se referem explicitamente a um "rei", não a governadores, e, portanto, parecem estar preocupados com o Império, em geral, e com sua capital, Roma. No entanto, os relatos dos poderes e esplendores dos governadores provinciais romanos, especialmente os do praefectus Aegypti, que residia no palácio dos antigos reis ptolomaicos e governava o país em seu lugar (loco regum), poderiam muito bem ter levado comentaristas do Extremo Oriente a confundir esses governadores com os reis locais. Além disso, o Hou Hanshu e o Weilüe alegam que Da Qin (não "Haixi") estabeleceu várias dezenas de "reinos dependentes" menores, que podem ser entendidos

\footnotetext{
${ }^{25}$ A mesma declaração pode, novamente, também ser encontrada no Hou Hanchi, e uma versão abreviada no Chinshu. Leslie, Gardner, 1996: 60 e 81.
}

Heródoto, Unifesp, Guarulhos, v.4, n.1 - 2019.1. p. 395-422

DOI: 10.34024/herodoto.2019.v4.10128 
como uma referência às províncias do Império Romano ou aos aliados orientais de Roma ${ }^{26}$.

Se estiverem corretas, essas observações revelam alguns detalhes importantes sobre a transmissão de informações do mundo mediterrâneo para o Extremo Oriente chinês. Acima de tudo, eles implicam que algumas informações reais e detalhadas sobre o Império Romano realmente chegaram à China durante os dois primeiros séculos EC. No entanto, parece que o conhecimento chinês do Império Romano (Da Qin) foi parcialmente defeituoso e amplamente restrito a informações sobre as províncias, especialmente o Egito. Isso, por sua vez, implica que a maior parte da informação sobre o Império Romano que foi registrada na China antiga se originou das províncias romanas orientais, especialmente do Egito. Isto combina com os relatos ou suposições sobre a rota marítima que a maioria dos "emissários" romanos das fontes chinesas tomaram. Finalmente, o fato de que os chineses não entendiam completamente o sistema governamental que eles registraram pode ser usado para indicar que eles não tinham mais nenhum conselho de alguém com conhecimento em primeira mão da administração provincial romana, o que, novamente, sugere que poucos indivíduos viajaram a distância total entre os dois impérios.

Os mercadores eram fontes bem conhecidas e importantes de informação no mundo antigo (Lee, 1993: 161-163; Austin, Rankov, 1995: 25-27). As notícias e dados que ofereciam de países distantes eram, muitas vezes, de primeira mão e, em todo caso, mais recentes do que as encontradas em tratados de geografia (Cf. Plin. NH 6, 31, 140. Paus. 3, 12, 4, 9, 21,4-5). Geógrafos do mundo romano, como Estrabão, Pausânias e Ptolomeu, reconheceram sua dívida com os comerciantes pelas informações (Strabo 2, 5, 12. Plin. NH 6, 31, 140. Paus. 1, 42, 5. Ptol. 1, 17, 3-4). Embora os comerciantes fossem, às vezes, criticados como fontes não confiáveis, eles, ocasionalmente, forneciam até mesmo inteligência estratégica ${ }^{27}$. Algumas dessas informações foram seguramente transmitidas oralmente (particularmente outros comerciantes), mas grande parte delas também foi

\footnotetext{
26 Esplendores: Tac., Hist. 1, 11, 1. Strabo 17, 1, 12. Para uma discussão recente e bibliografia mais aprofundada, cf. Jördens, 2009: 11-15, Pont, 2009: 185-211. Reinos dependentes: Hou Hanshu 88 (Hill, 2004: sect. 11, Hill, 2015, vol. I: 23). Cf. Leslie, Gardner, 1996: 47. Wielüe 15ff, cf. sect. 11 e 14 (a referência aqui depende do rei): Hill, 2004: sect. 15ff, e Leslie, Gardner, 1996: 71 e 76-78. Sobre os aliados orientais de Roma e seu papel no comércio de longa distância, cf. Speidel, inédito.

27 Não confiáveis: Strabo 15, 1, 3-4. Plin. NH 12, 42, 85. Ptol. 1, 11, 4 e 7-8. Eunap. fr. 66, 2 / 13-14. Inteligência estratégica: Xen, Hell. 3, 4, 1. Plin. NH 6, 24, 88. Tac. Agr. 24. Cf. also Plut. Nik. 30. Cf. Sánchez Hernández, 2015: 7.
}

Heródoto, Unifesp, Guarulhos, v.4, n.1 - 2019.1. p. 395-422

DOI: 10.34024/herodoto.2019.v4.10128 
registrada em documentos perdidos ${ }^{28}$. Como mencionado acima, tais documentos também forneceram a maioria dos dados subjacentes no Extremo Oriente contidos nos escritos de antigos geógrafos e textos ocidentais, como o Periplus Maris Erythraei (De La Vaissière, 2009; De Romanis, 2016). É notável, portanto, que os chineses Hou Hanshu e Weilüe contenham parágrafos com conteúdo e estruturas que se assemelham aos do Periplus Maris Erythraei, mas, aparentemente, não possuam contrapartidas comparáveis nas seções que tratam de outros países (Hou Hanshu 88 (Hill, 2004: sect. 12; Hill, 2015, vol. I: 25-27), Weilüe 12 e 14-20 (Hill, 2004: sect. 12, 14-20)). Talvez, portanto, essas características formais, aparentemente únicas, nas seções sobre Da Qin sejam traços da transmissão de informações por mercadores romanos.

Seja como for, como mencionado acima, as informações sobre Roma raramente chegam diretamente à China. Isso também se reflete no fato de que algumas das informações incluídas nas seções do Hou Hanshu e do Weilüe sobre Da Qin parecem ter origens chinesas e não romanas. Em um exemplo, pelo menos, parece que as realidades culturais e administrativas do antigo Império Chinês contaminaram as informações do Império Romano. Assim, o conhecimento das instituições chinesas locais parece ter afetado as breves descrições do sistema imperial romano de transporte e comunicação. Tanto o Hou Hanshu quanto o Weilüe referem-se em detalhes surpreendentes aos pontos de parada deste sistema, às distâncias entre eles e à sua aparência: "Em intervalos eles estabeleceram relés postais, todos rebocados e caiados... A cada dez $l i[4.2 \mathrm{~km}]$ existe um ponto postal e a cada trinta li [12,5 km] uma estação postal" (Hou Hanshu 88 (Hill, 2004: sect. 11-12; Hill, 2015, vol. I: 26-27), cf. Leslie, Gardner, 1996: 47 e 52. Para a respectiva passagem no Weilüe, Hill, 2004: sect. 11 e Leslie, Gardner, 1996: 70, cf. Hoppál, 2011: 282). O objetivo dessa instituição romana também foi registrado pelos chineses: "As estações de retransmissão foram estabelecidas em posições estratégicas, permitindo que ordens viagem rapidamente entre estações postais em todas as estações" (Hou Hanshu 88 (Hill, 2004: sect. 28; Hill, 2015, vol. I: 55)). Estas declarações foram entendidas como referindo-se à vehiculatio ou cursus publicus do Império Romano, já que um dos propósitos dessa instituição romana era, de fato, transmitir comunicações oficiais rapidamente, e a descrição de sua infraestrutura nas fontes chinesas parece ser exata o suficiente (Cf. Kolb, 2000).

No entanto, as distâncias de $10 \mathrm{li}(4,2 \mathrm{~km})$ entre os pontos postais e $30 \mathrm{li}$ $(12,5 \mathrm{~km})$ entre as maiores estações postais não são confirmadas por fontes

28 Sobre a perda desta literatura, cf. as citações acima.

Heródoto, Unifesp, Guarulhos, v.4, n.1 - 2019.1. p. 395-422

DOI: 10.34024/herodoto.2019.v4.10128 
romanas. Embora os itinerários romanos listem locais de parada pequenos e grandes, eles são registrados em intervalos de 6 a 12 milhas (c. 9 e 18 km) e 25 milhas $(37 \mathrm{~km})$, que correspondem a cerca de meio dia e um dia inteiro de viagem a pé, respectivamente. Isso equivale a duas ou três vezes a distância indicada pelas fontes chinesas (Kolb, 2000: 212-213). Em particular, as distâncias muito curtas de $4,2 \mathrm{~km}$ não estavam em uso no Império Romano. Talvez houvesse confusão entre os correios e as pousadas locais, que provavelmente se situavam em intervalos curtos nas proximidades das cidades. Contudo, outra solução, talvez mais plausível, poderia ser que o conhecimento dos autores chineses de seu próprio sistema postal contaminou o relato sobre Da Qin, pois esses textos insistem que os sistemas postais romano e chinês eram praticamente idênticos: "Eles têm... estações postais como nós as temos na China" (Weilüe 11 (Hill, 2004: sec. 11). Cf.. Leslie, Gardner, 1996: 70. Ver também Hirth, 1885: 44 (Chinshu) e 70; Leslie, Gardner, 1996: 81). É particularmente sugestivo, portanto, que as fontes chinesas do Império Qin mencionem distâncias curtas de 2,6 milhas entre as paradas postais, que equivalem a distância de $10 \mathrm{li}(4,2 \mathrm{~km})$, como registrado no Hou Hanshu e no Weilüe (Chang, 2007: 54, também menciona intervalos de 5,2 milhas $(8,4 \mathrm{~km})$ ). A identificação dessas instituições importantes tanto na China quanto na "Grande China" (Da Qin / Roma) pode, portanto, ter encorajado os autores e compiladores chineses, que não conseguiram encontrar a informação correta nos documentos disponíveis sobre Da Qin, nem perguntar a alguém que sabia, a inserir os dados que faltavam baseados em seu conhecimento das instituições chinesas (Olbricht, 1954: 36; Loewe, 2006: 106-118).

\section{Conclusões}

Apesar da inclusão de dados utópicos e defeituosos, os textos historiográficos chineses revelam-se fontes surpreendentemente ricas sobre o fluxo de informações reais entre os impérios romano e chinês. Ao contrário do que geralmente se acredita, uma porcentagem significativa da informação armazenada no Hou Hanshu e no Weilüe (e outros textos) pode ser reconhecida como baseada em dados reais do Império Romano. O interesse chinês no mundo romano assemelhava-se ao interesse romano na China: ambos os lados mostravam um interesse particular em aspectos do comércio, mas ambos também buscavam mais informações do que aquelas comercialmente relevantes, pois os respectivos relatos também incluíam dados geográficos, políticos, administrativos e culturais. No entanto, os textos chineses sugerem fortemente que (a maior parte das) informações detalhadas sobre o Império Romano que chegaram a China se 
originaram e, principalmente, faziam referência às províncias orientais do Imperium Romanum, em particular, do Egito. Notavelmente, tal informação alcançou a China recorrentemente (embora não frequentemente), principalmente (mas talvez nem sempre) indiretamente, e quase exclusivamente através dos canais propiciados pelo comércio de longa distância. A única exceção, aquela em que detalhes históricos suficientes estão presentes para torná-la credível, a missão do enviado de Ban Chao, Gan Ying, em 97 EC, teve um impacto extraordinariamente forte sobre os relatos chineses sobreviventes sobre o Império Romano, evidentemente por causa da posição da pessoa que o transmitiu (Hou Hanshu 88 (Hill, 2004: sect. 1; Hill, 2015, vol. I: 13). Mas o relatório de Gan Ying sobre o Imperium Romanum também foi indireto e, em última análise, enraizado (em parte, pelo menos) em relatos de comerciantes. Barreiras linguísticas e os métodos para superá-los não são descritos em nossas fontes. Seus efeitos sobre o status dos relatos romanos e chineses preservados não são, portanto, aparentes. A transmissão de informações geográficas, políticas, administrativas e culturais complexas por meio de redes de comércio de longa distância afetou não apenas a qualidade e a variedade das informações fornecidas, mas também prejudicou os dados e deixou marcas reconhecíveis e características nos documentos escritos que sobreviveram. Tais defeitos parecem revelar a ausência de possibilidades para verificar as informações antes de serem inseridas nos registros oficiais chineses. Em todo caso, tais lacunas eram muitas vezes simplesmente preenchidas com histórias fantasiosas e estereótipos, ou dados reais de outros lugares, antes que o resultado fosse finalmente adaptado às visões utópicas de uma "Grande China" (Da Qin) do outro lado do mundo habitado.

A enorme influência de obras escritas e relatos de comerciantes de longa distância nos relatos ocidentais sobreviventes sobre China e o Extremo Oriente também é evidente. Entretanto, os registros romanos sobreviventes sobre a China antiga diferem de seus correspondentes chineses em um aspecto essencial: nenhum registro oficial do ocidente sobreviveu. Também não há relatos confiáveis de missões oficiais de reconhecimento ou embaixadas à corte chinesa. Se baseados em fatos verdadeiros, os emissários romanos mencionados na historiografia chinesa estão mais propensos a serem mercadores. Além disso, a outrora abundante literatura sobre viagens do mundo ocidental (e seus textos derivados) que sem dúvida esclareceria a Ásia Central e o Extremo Oriente na Antiguidade está inteiramente perdida. Isso é ainda mais lamentável quando os textos que sobreviveram não fizeram uso total de todos os dados que estavam disponíveis no Império Romano (como o Periplus Maris Erythraei ilustra). Não há razão, portanto, para acreditar que a informação

Heródoto, Unifesp, Guarulhos, v.4, n.1 - 2019.1. p. 395-422

DOI: 10.34024/herodoto.2019.v4.10128 
sobre a China antiga, conforme registrada pelas obras existentes de geógrafos ocidentais, reflete a extensão do conhecimento que esteve presente na Bacia do Mediterrâneo sob o domínio romano. Finalmente, não há nada nos registros escritos do mundo chinês ou do romano que sugira que os dados transmitidos de um mundo inspiraram a inovação no outro. Detalhes são apresentados como curiosidades, não como exemplos. Atitudes de superioridade cultural são aparentes nos relatos de ambos os mundos.

\section{Referências bibliográficas}

ARBACH, M. SCHIETTECATTE, J. La diplomatie et l'aristocratie tribale du royaume de Saba d'après une inscription du IIle siècle de l'ère chrétienne. In: CRAI, 2015, pp. 371-398.

AUSTIN, N.J.E. RANKOV, N.B. Exploratio: Military and Political Intelligence in the Roman World from the Second Punic War to the Battle of Adrianople. Londres: Routledge, 1995.

BIELENSTEIN, H., The Restoration of the Han Dynasty, with Prolegomena on the Historiography of the Hou Han Shu. Göteborg: Elandersboktr,1953.

BREEZE, D.J., DOBSON, B. Hadrian's Wall. Londres: Penguin, 1976.

CAMPBELL, D.B. A Chinese Puzzle for the Romans. In: Historia, 38, 1989, pp 371-376.

CAMPBELL, D.B. Did the Romans Have Links with the Far East? Rome and China. In: Ancient Warfare, IX-2, 2015, pp. 45-49.

CHANG, Ch. The Rise of the Chinese Empire, vol. 1. Ann Arbor: University of Michigan Press, 2007.

CHAVANNES, É. Les pays d'Occident d'après le Heou Han chou. In: T'oungpao, 8, 1907, pp. 149-244. 519-571.

Les pays d'Occident d'après le Wei lio. In: T'oungpao, 6, 1905, pp. 
CREEL, H.G. Sinism. A Study of the Evolution of the Chinese World-View. Chicago: The Open Court Publishing Co., 1929.

COLORU, O. TRAINA, G. LYCAS, A. The Parthians. In: BERNARDINI, M. BONORA, G. L. TRAINA, G. (Eds.). Turkmenistan. Histories of a Country, Cities, and a Desert. Turin: Umberto Allemandi, 2016, pp. 49-58.

DE LA VAISSIÈRe, E. The Triple System of Orography in Ptolemy's Xinjiang. In: SUNDERMANN, W. HINTZE, A. BLOIS, F. (Eds). Exegisti Monumenta. Festschrift in Honour of Nicholas Sims-Williams. Wiesbaden: Harrassowitz, 2009, pp. 527-535.

DE ROMANIS, F. An Exceptional Survivor and Its Submerged Background: The Periplus Maris Erythraei and the Indian Ocean Travelogue Tradition. In: COLESANTI, G. LULLI, L. (Eds.) Submerged Literature in Ancient Greek Culture. Case Studies. Berlin: de Gruyter, 2016, pp. 97-110.

DUECK, D. Geography in Classical Antiquity. Cambridge: Cambridge University Press, 2012.

FAUCONNIER, B. Graeco-Roman Merchants in the Indian Ocean: Revealing a Multicultural Trade. In: BOUSSAC, M. SALLES, J. YON, J-B. (Eds). Autour du "Périple de la mer Érythrée." Topoi, Supplement 11. Paris: Editions De Boccard, 2012, pp. 75-109.

FENG, L. Early China. A Social and Cultural History. Cambridge: Cambridge University Press, 2013.

FERGUSON, J. China and Rome. In: ANRW II, 9/2, 1978, pp. 581-603.

FIBIGER BANG, P. Commanding and Consuming the World. In: SCHEIDEL, W. (Ed.). Rome and China. Oxford: Oxford University Press, 2009, pp. 100120.

GIZEWSKI, C. KOLB, R. Th. Review" of Michael Kordosis, China and the Greek World. An Introduction to Greec[sic]-Chinese Studies with Special Reference to the Chinese Sources. I: Hellenistic-Roman-Early Byzantine Period (2nd c. BC-6th c. $A D)$. In: Klio, 77, 1995, pp. 481-489.

GRAF, D.F. The Roman East from the Chinese Perspective. In: AAS, 42, 1992, pp. 199-216.

The Silk Road between Syria and China. In: WILSON, A. I. BOWMAN, A. K. (Eds.). Trade, Commerce, and the State in the Roman World. Oxford: Oxford University Press, 2017 (No prelo).

Heródoto, Unifesp, Guarulhos, v.4, n.1 - 2019.1. p. 395-422

DOI: $10.34024 /$ herodoto.2019.v4.10128 
HEIL, M. SCHULZ, R. Who was Maes Titianus? In: JAC, 30, 2015, pp. 72-84.

HILL, J.E. The Peoples of the West from the Weilüe by Yu Huan: A Third Century Chinese Account Composed between 239 and 265 CE. Draft Annotated English Translation (September 2004). Disponível em: http://depts.washington.edu/silkroad/texts/weilue/weilue.html.

Acesso em 29 de abril de 2016.

Through the Jade Gate - China to Rome. A Study of the Silk Routes during the Later Han Dynasty 1st to 2nd Centuries CE. An Annotated Translation of the Hou Hanshu "The Chronicle on the Western Regions". Expanded and Updated. Vol. I-II. Reino Unido: Marston Gate, 2015.

HILLERS, D.R. CUSSINI, E. Palmyrene Aramaic Texts. Baltimore: Johns Hopkins University Press, 1995.

HIRTH, F. China and the Roman Orient. Shanghai: Kelly \& Walsh, 1885.

HOPPÁL, K. The Roman Empire According to the Ancient Chinese Sources. In: Acta Ant. Hung, 51, 2011, pp. 263-306.

JÖRDENS, A. Statthalterliche Verwaltung in der römischen Kaiserzeit. Studien zum Praefectus Aegypti. Stuttgart: Steiner Verlag, 2009.

KOLB, A. Transport und Nachrichtentransfer im Römischen Reich. Berlin: AkademieVerlag, 2000.

Kolb, A. SPEIDEL, M.A. Perceptions from Beyond: Some Observations on NonRoman Assessments of the Roman Empire from the Great Eastern Trade Routes. In: JAC, 30, 2015, pp. 117-149.

KORDOSIS, M. China and the Greek World. An Introduction to Greec[sic]Chinese Studies with Special Reference to the Chinese Sources. I: HellenisticRoman-Early Byzantine Period (2nd c. BC-6th c. AD) (Historicographica Meletemata 2) Thessaloniki: publisher not identified, 1992

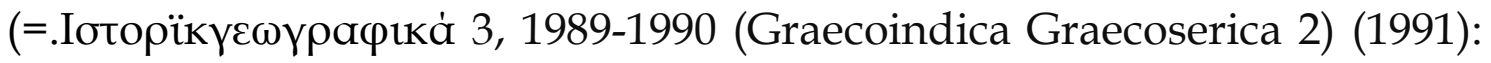
143-253).

LAUFER, B. The Name China. In: T'oungPao, 2nd Series, 13, 1913, pp. 719726.

LEE, A.D. Information and Frontiers. Roman Foreign Relations in Late Antiquity. Cambridge: Cambridge University Press, 1993. 
LESLIE, D.D. GARDINER, K.H. The Roman Empire in Chinese Sources. Rome: Bardi, 1996.

LEWIS, M.E. The Early Chinese Empires: Qin and Han. Cambridge, MA: The Belknap Press of Harvard University Press, 2007.

LIU, X. The Silk Road in the World History. Oxford: Oxford University Press, 2010.

LOEWE, M. The Government of the Qin and Han Empires 221BCE-220 CE. Indianapolis: Hackett Publishing Co. Inc., 2006.

. Introduction. In: TWITCHETT, D. LOEWE, M. (Eds.). The Cambridge History of China. Vol. 1. The Ch' in and Han Empires, 221 B.C. - A.D. 220. Cambridge: Cambridge University Press, 1986.

Knowledge of Other Cultures in China's Early Empires. In: RAAFLAUB, Kurt A. TALBERT, Richard J. A. (Eds.). Geography and Ethnography: Perceptions of the World in Pre-Modern Societies. Oxford: Wiley, 2010, pp. 74-88.

MANSVELT BECK, B.J. The Treatises of Later Han. Their Author, Sources, Contents and Place in Chinese Historiography. Leiden: Brill, 1990.

MCLAUGHLIN, R. Rome and the Distant East. Trade Routes to the Ancient Lands of Arabia, India and China. London: Bloomsbury Publishing, 2010.

MILLER, M.C. Athens and Persia in the Fifth Century BC: A Study in Cultural Receptivity. Cambridge: Cambridge University Press, 1997.

NAEREBOUT, F.G. Review of Michael Kordosis, China and the Greek World. An Introduction to Greec[sic]-Chinese Studies with Special Reference to the Chinese Sources. I: Hellenistic-Roman-Early Byzantine Period (2nd c. BC-6th c. AD). In: Mnemosyne, 49, 1996, pp. 373-377.

NICKEL, L. The First Emperor and Sculpture in China. In: Bulletin of the School of Oriental and African Studies, 76/3, 2013, pp. 413-447.

OLBRICHT, P. Das Postwesen in China unter der Mongolenherrschaft im 13.und 14. Jahrhundert. Wiesbaden: Harrassowitz, 1954.

OLBRYCHT, M.J. Die Geschichte der Seidenstraße in antiker Zeit. In: MÜLLER, S. Die Krim. Goldene Insel im Schwarzen Meer. Begleitbuch zur Ausstellung in Bonn. Darmstadt: Primus, 2013, pp. 67-87.

Heródoto, Unifesp, Guarulhos, v.4, n.1 - 2019.1. p. 395-422

DOI: 10.34024/herodoto.2019.v4.10128 
PAUL, B. De l'Euphrate à la Chine avec la caravane de Maès Titianos (ca.100 apr. n. è.). In: CRAI, 149, 2005, pp. 929-969.

POINSOTTE, J.-M. Les Romains et la Chine: réalités et mythes. In: MEFRA, 91, 1979, pp. 431-479.

PONT, A.-V. Rituels civiques (apantêsis et acclamations) et gouverneurs à l'époque romaine en Asie Mineure. In: HEKSTER, O. SCHMIDT-HOFNER, S. WITSCHEL, C. Ritual Dynamics and Religious Change in the Roman Empire. Leiden: Brill, 2009, pp. 185-211.

PULLEYBLANK, E.G. The Roman Empire as Known to Han China. In: JAOS, 119, 1999, pp. 71-79.

RASCHKE, M.G. New Studies in Roman Commerce with the East. In: ANRW, II/9, 1978, pp. 604-1233.

RUFFING, K. Seidenhandel in der römischen Kaiserzeit. In: DROSS-KRÜPE, K. (Ed.). Textile, Trade, and Distribution in Antiquity. Wiesbaden: Harrossowitz, 2014, pp. 71-81.

SÁNCHEZ HERNÁNDEZ, J.P. Pausanias and Rome's Eastern Trade. In: Mnemosyne, 2015, pp. 1-23. DOI: 10.1163/1568525X-12341878.

SCHEIDEL, W. "Introduction." In: Rome and China. Oxford: Oxford University Press, 2009, pp. 3-10.

Introduction. In: . State Power in Ancient China and Rome. Oxford: Oxford University Press, 2015, pp. 3-10.

SCHULZ, R. Abenteurer der Ferne. Die grossen Entdeckungsfahrten und das Weltwissen der Antike. Stuttgart: Klett-Cotta, 2016.

SPEIDEL, M.A. Almaqah in Rom? Epigraphisches zu den römischsabäischen Beziehungen in der Hohen Kaiserzeit. In: ZPE, 194, 2015, 241 ff.

. Fernhandel und Freundschaft. Zu Roms amici an den Handelsrouten nach Südarabien und Indien. In: Orbis Terrarum, 14 (no prelo).

Wars, Trade and Treaties. New, Revised, and Neglected Sources for Political, Diplomatic, and Military Aspects of Imperial Rome's Relations with India and the Red Sea Basin, from Augustus to Diocletian." In: MATHEW, K. S. (Ed.). Imperial Rome, Indian Ocean Regions and Muziris: New Perspectives On Maritime Trade. New Dehli: Manohar, 2015, pp. 83-128. 
STEVENS, C.E. Hadrian and Hadrian's Wall. In: Latomus, 14, 1955, pp. 384403.

WALTER, J. Antikes Griechenland und Altes China: Die Entstehung früher Fremdbilder im Wirtschafts- und Kommunikationssystem Seidenstraße. Berlin: Wissenschaftlicher Verlag, 2013.

WALTER, J. Die Vorstellungen über das ostasiatische Ende der Seidenstrasse in den antiken griechischen Quellen. In: GÖBL, J. ZECH, T. Exportschlager Kultureller Austausch, Wirtschaftliche Beziehungen und transnationale Entwicklungen in der antiken Welt. München: Utz, 2009, pp. 86-106.

WANG, Q.E. History, Space, and Ethnicity: The Chinese Worldview. In: JWH, 10, 1999, pp. 285-305.

WELLER, F. Mahacina - Arabia Felix. In: Asia Major, 4, 1927, pp. 46.

WHEELER, M. Rome beyond the Imperial Frontiers. London: Bell and Sons, 1954.

YING, L. Ruler of the Treasure Country: The Image of the Roman Empire in Chinese Society from the First to the Fourth Century AD. In: Latomus, 63, 2004, pp. 327-339.

YOUNG, G.K. Rome's Eastern Trade: International Commerce and Imperial Policy, 31 BCE - CE 305. London: Routledge, 2001.

YU, T. China and the Ancient Mediterranean World: A Survey of Ancient Chinese Sources. In: Sino-Platonic Papers, 242, 2013, pp. 1-268.

ZIETHEN, G. Legationes Externae in der frührömischen Kaiserzeit: INDI -

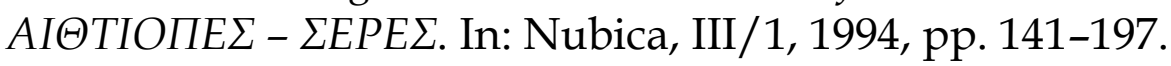

